NIEVA, Jordi. "Seis conceptos en busca de un objetivo: jurisdicción, acción, proceso, derechos, pena y delito".

Polít. crim. Vol. 12, № 23 (Julio 2017), Art. 4, pp. 103-123.

[http://www.politicacriminal.cl/Vol_12/n_23/Vol12N23A4.pdf]

\title{
Seis conceptos en busca de un objetivo: jurisdicción, acción, proceso, derechos, pena y delito
}

\author{
Six concepts in search of a goal: jurisdiction, action, process, \\ rights, penalty, crime \\ Jordi Nieva Fenoll \\ Catedrático de Derecho Procesal, Universitat de Barcelona \\ jordinieva@ub.edu
}

\section{Resumen}

Con frecuencia acostumbra a verse al Derecho Penal y al Derecho Procesal como dos universos separados. En realidad, se trata simplemente de materias que fueron especializadas al ser difícil que un solo especialista sea un auténtico experto en ambas. Con todo, ello no puede producir una disociación en su estudio, sino que ambas ramas del Derecho deben tender a un fin común. Ahora bien: ¿cuál es ese fin? Conocerlo es importante, sobre todo, para poder legislar debidamente, sin caer en el dogmatismo ni en el populismo punitivo. En el artículo se acaba concluyendo que tanto Derecho Penal como Derecho procesal persiguen muy claramente la búsqueda de un consenso en cuanto a lo más odiado por una sociedad. Tal conclusión se demuestra desde el punto de vista histórico, teórico y práctico. El legislador sistematiza en una ley, el Código Penal, lo que la sociedad más rechaza. El juez busca ese mismo resultado a través de su juicio, y sobre todo a través de la motivación del mismo, legitimando así todo el sistema.

Palabras clave: Sistema integral, principios, juicio.

\begin{abstract}
Criminal Law and Procedural Law are often seen as two separate universes. In fact, they are matters that were specialized only because it was hard for a single specialist to be a real expert on both. However, this specialization cannot produce a dissociation in their study. Both subjects should aim at a common end. But, which is this end? Knowing this end is important, above all, to be able to legislate properly, without falling into dogmatism or punitive populism. The article ends up concluding that both Criminal Law and Procedural Law very clearly search for a consensus on what society hates the most. This conclusion is demonstrated from the historical, theoretical and practical point of view. The legislator systematizes in a law, the Penal Code, what society more intensely rejects. The judge seeks the same goal through his judgment, and above all through its motivation, justifying this way the whole system.
\end{abstract}

Key words: Integral system, principles, judgment. 
NIEVA, Jordi. "Seis conceptos en busca de un objetivo: jurisdicción, acción, proceso, derechos, pena y delito".

\section{Introducción}

A veces el Derecho penal hace preguntas al Derecho procesal para las que puede parecer que éste no tiene respuesta. La dogmática penal ha elaborado una riquísima teoría del delito $^{1}$ cuyo fin último es conocer, en pocas palabras, por qué o para qué existe el Derecho penal. Para ello es preciso saber qué es lo que se castiga, qué posibles causas de justificación pueden existir al hecho perpetrado que lesionó o puso en peligro el bien jurídico, y finalmente si existía un componente volitivo suficiente en el sujeto que merezca sanción. ¿Pero por qué ha de merecer un sujeto sanción? ¿Queremos castigar para "compensar" el mal realizado? ¿Queremos prevenir que sucedan hechos parecidos asustando con la pena? ¿Queremos castigar al individuo para que entienda que está mal lo que hizo y decida no volver a delinquir? Y además, ¿para qué hacemos todo ello? Si de lo que se trata es de conservar un estado de convivencia social satisfactorio en la medida de lo que, efectivamente, nos parezca razonable en cada momento, ¿qué es mejor? ¿Extirpar? ¿Tratar? ¿Curar? ¿Asustar? El Derecho penal lleva ya bastante tiempo formulándose, de un modo u otro, estas preguntas.

Varios autores han introducido la variable del proceso jurisdiccional en la discusión ${ }^{2}$. Si convenimos pacíficamente en que sin proceso no hay pena posible, a fin de entender para qué sirve el Derecho penal será útil analizar también para qué sirve el Derecho procesal, pero... ¿el Derecho procesal se ha formulado la pregunta de para qué sirve?

Las líneas que seguirán describirán las respuestas que, de un modo u otro, se han dado al interrogante. Quedará por ver si algo de ello es aprovechable para la construcción de ese sistema integral, o se trata simplemente de una opción teórica sin relevancia práctica o, bien al contrario, encontrar esa idea guía común nos permitirá articular mejor la respuesta de todo este sector del ordenamiento.

Tómese en cuenta una advertencia previa. Es posible que no se hubiera entrado en este debate de no poseer el ministerio fiscal alemán las facultades derivadas del principio de oportunidad ( $\$ \S 153$ y ss. StPO $)^{3}$, más frecuentes de lo que parece -un $27 \%$ de los casos ${ }^{4}-$ a veces sorprendentes ${ }^{5}$-aunque también benefactoras ${ }^{6}-$, de renuncia a la persecución penal,

\footnotetext{
${ }^{1}$ Una aproximación general absolutamente diáfana puede verse en MIR PUIG, Santiago, Derecho Penal, parte general, Barcelona: Reppertor, 2011, pp. 135 y ss.

${ }^{2}$ Ver por todos AAVV, El sistema integral del Derecho penal, Madrid: Marcial Pons, 2004. RAGUÉS i VALLÈS, Ramón, "La función del proceso en el sistema integral del Derecho penal: una valoración crítica del estado de la cuestión”, en: MAQUEDA, María Luisa; MARTÍN, María; VENTURA, Arturo (Coords.), Derecho Penal para un estado social y democrático de derecho: estudios penales en homenaje al profesor Emilio Octavio de Toledo y Ubieto, Madrid: Universidad Complutense de Madrid, Facultad de Derecho, Servicio de Publicaciones, 2016, pp. 1203 y ss.

${ }^{3}$ Sobre las mismas, KÜHNE, Hans Heiner, Strafprozessrecht, Heidelberg: C.F. Müller, 2015, pp. 382 y ss.

${ }^{4}$ Como reporta KÜHNE, Strafprozessrecht, cit. nota $n^{\circ} 3$, p. 382.

${ }^{5}$ \& 153d StPO. Absehen von der Verfolgung bei Staatsschutzdelikten wegen überwiegender öffentlicher Interessen. (1) Der Generalbundesanwalt kann von der Verfolgung von Straftaten der in $\$ 74 a$ Abs. 1 Nr. 2 bis 6 und in $\$ 120$ Abs. 1 Nr. 2 bis 7 des Gerichtsverfassungsgesetzes bezeichneten Art absehen, wenn die Durchführung des Verfahrens die Gefahr eines schweren Nachteils für die Bundesrepublik Deutschland herbeiführen würde oder wenn der Verfolgung sonstige überwiegende öffentliche Interessen entgegenstehen.
} 
Polít. crim. Vol. 12, No 23 (Julio 2017), Art. 4, pp. 103-123.

[http://www.politicacriminal.cl/Vol_12/n_23/Vol12N23A4.pdf]

y que en ocasiones poco o nada tienen que ver, con frecuencia, con los fines del Derecho penal, y mucho menos con el Derecho procesal, sino con intereses simplemente políticos. A partir de ahí se han ido analizando los "obstáculos" que puede poner el proceso a la efectividad del Derecho penal, quizás desenfocando un tanto la cuestión, habida cuenta de que se han metido en el mismo saco instituciones de esencia muy dispar, como el sobreseimiento, la prueba, la prisión provisional y hasta la presunción de inocencia ${ }^{7}$.

Con todo, el estudio no ha dejado de ser provechoso, en el sentido de que se consiga o no ese sistema integral, siempre es útil saber por qué existen las instituciones del ordenamiento, dado que conocer esas razones ayuda a planificar mejor las reformas, por ejemplo. Además, el hallazgo de ese objetivo común puede comportar una benéfica función de estabilización teleológica de todo el sector que puede tener importantes beneficios sociales a largo plazo.

\section{Los principios del proceso, los conceptos fundamentales del Derecho Procesal y la prohibición de autotutela.}

Lo más parecido a una búsqueda de los fines del Derecho procesal ha venido en España, Italia y América Latina -no propiamente en Alemania- del estudio de sus llamados "conceptos fundamentales", así como en parte de los "principios del proceso", en el que las categorías alemanas sí que han influido más modernamente ${ }^{8}$.

El primer estudio surge, en realidad, de una polémica entre civilistas - o romanistas- sobre el concepto de acción ${ }^{9}$, que después referiré, al que se fueron superponiendo las categorías

(2) Ist die Klage bereits erhoben, so kann der Generalbundesanwalt unter den in Absatz 1 bezeichneten Voraussetzungen die Klage in jeder Lage des Verfahrens zurücknehmen und das Verfahren einstellen.

${ }^{6}$ Es especialmente interesante la derivada del § 154d StPO, porque de ser introducido en España, evitaría un sinnúmero de querellas malintencionadas: Verfolgung bei zivil- oder verwaltungsrechtlicher Vorfrage. Hängt die Erhebung der öffentlichen Klage wegen eines Vergehens von der Beurteilung einer Frage ab, die nach bürgerlichem Recht oder nach Verwaltungsrecht zu beurteilen ist, so kann die Staatsanwaltschaft zur Austragung der Frage im bürgerlichen Streitverfahren oder im Verwaltungsstreitverfahren eine Frist bestimmen. Hiervon ist der Anzeigende zu benachrichtigen. Nach fruchtlosem Ablauf der Frist kann die Staatsanwaltschaft das Verfahren einstellen.

${ }^{7}$ Ver WOLTER, Jürgen, "Estudio sobre la dogmática y la ordenación de las causas materiales de exclusión, del sobreseimiento del proceso, de la renuncia a la pena y de la atenuación de la misma. Estructuras de un sistema integral que abarque el delito, el proceso penal y la determinación de la pena", pp. 42 y ss., y FREUND, Georg, "Sobre la función legitimadora de la idea de fin en el sistema integral de Derecho penal", pp. 108 y ss., ambos en: AAVV, El sistema integral, cit. nota ${ }^{\circ} 2$.

JAUERNIG, Othmar; HESS, Burkhard, Zivilprozessrecht, München: C.H. Beck, 2011, p. 93. ROSENBERG, Leo; SCHWAB, Karl Heinz; GOTTWALD, Peter, Zivilprozeßrecht, München: C.H. Beck, 2010, pp. 395-396.

${ }^{9}$ WINDSCHEID, Bernhard, Die Actio des römischen zivilrechts vom Standpunkte des heutigen Rechts, Düsseldorf, 1856. MUTHER, Theodor, Zur Lehre von der römischen Actio, dem heutigen Klagerecht, der Litiskontestation und der Singularsukzession in obligationen. Eine Kritik des windscheidschen Buchs "die Actio des römischen Zivilrechts". WINDSCHEID, Bernhard, Die Actio. Abwehr gegen Theodor Muther, Düsseldorf, 1857. Las tres obras están recopiladas en un único tomo en el facsímil WINDSCHEID, Bernhard; MUTHER, Theodor, Die actio des römischen zivilrechts, Darmstadt: Scientia Verlag Aalen, $2^{\mathrm{a}}$ ed., 1984. 
NIEVA, Jordi. "Seis conceptos en busca de un objetivo: jurisdicción, acción, proceso, derechos, pena y delito".

de "jurisdicción" y "proceso", con aportaciones también de la doctrina francesa ${ }^{10}$ en cuanto a este último concepto.

El estudio de los principios del proceso es, como se ha dicho, más reciente, aunque de origen mucho más antiguo ${ }^{11}$. Pero conviene saber que dicho estudio es un simple atisbo, en muchas ocasiones, del de los derechos fundamentales del proceso, en especial el derecho de defensa ${ }^{12}$.

Sin embargo, no ha habido un planteamiento global de todo ello como enfocado a un solo objetivo. Se ha dado por hecho que ese objetivo era obvio y existía, pero ciertamente no se ha reflexionado demasiado sobre el mismo. En el mejor de los casos se ha hablado de la "justa composición de la litis"13, o aún más en general y a vuelapluma de la "Justicia", o hasta de la "paz social". Pero la definición de lo que sea un conflicto o la misma justicia se ha ido dejando, en realidad, de lado, aunque haya existido debate al respecto ${ }^{14}$.

Sin embargo, sí ha habido una parte de los autores que anunciaron una conclusión que ha sido aceptada unánimemente y sin dificultad por toda la doctrina: el Derecho procesal tiene como fin la evitación de la autotutela, es decir, de la venganza privada ${ }^{15}$. De hecho, se acostumbra a describir el mundo antiguo como un lugar dominado por esa venganza o autogestión de los asuntos propios de naturaleza violenta. El proceso jurisdiccional trajo la heterotutela, el actus trium personarum de Bulgaro ${ }^{16}$, que supera esa venganza simplemente unilateral -más bien bilateral- en beneficio del recurso a un tercero que resuelva el conflicto. Todo apunta a que dicho tercero en un principio pudo ser la propia comunidad en la que vivían los contendientes, que desempeñaba funciones que estaban entre la jurisdicción y la mediación ${ }^{17}$. Más adelante, o contemporáneamente -nunca lo sabremos-, el vulgo se sintetizó en una única persona o en un grupo de escogidos, lo que dio a luz a la figura del juez en su variedad de juzgador único o de jurado. Si lo hicieron por comodidad, para no implicar a toda la comunidad en el conflicto, o bien porque el tercero

10 DE GUENYVEAU, Arnault, Du quasi contrat judiciaire, Poitiers: Dupré, 1859, pp. 13-14. DÉMOLOMBE, Jean Charles Florent, Cours de Code Napoléon, t. 29, Paris: A. Lahure, 1879, pp. 179 y ss.

${ }^{11}$ DURANDUS, Speculum iuris, parte II, Venecia: Conradi, 1585, De Sententia, § 5, 1. pp. 784-785, aunque se remonta más atrás, hasta AZZONE (o AZO o AZÓN), Brocardica (aurea). sive generalia iuris, Basilea: Eusebium Episcopum, 1567, rúbrica XX, p. 237, y ACCURSIUS, Corporis Iustinianaei Digestum Vetus, seu Pandectarum, Vol. 6, Lyon: Sumptibus Horatii Cardon, 1604, p. 17: "Iudex debet ferre sententiam, secundum allegata et probata, non secundum conscientiam".

${ }^{12}$ Lo explico en NIEVA FENOLL, Jordi, Derecho Procesal I. Introducción, Madrid: Marcial Pons, 2014, pp. 122 y ss.

${ }^{13}$ CARNELUTTI, Francesco, "Ancora sulla lite nel processo penale", en: EL MISMO, Studi di Diritto Processuale, Padova: CEDAM, 1939, p. 58.

${ }^{14}$ Ver uno de los últimos en SEN, Amartya, The Idea of Justice, Cambridge: Allen Lane/Penguin Books, 2009.

15 SERRA DOMÍNGUEZ, Manuel, “Jurisdicción”, en: EL MISMO, Estudios de Derecho Procesal, Barcelona: Ariel, 1969, p. 21.

${ }^{16}$ BULGARUS, "Summa de iudiciis", en: WUNDERLICH, Agathon, Anécdota quae processum civilem spectant, Göttingen: Vandenhoeck et Ruprecht, 1841.

${ }^{17}$ MALINOWSKI, Bronislaw, Crimen y costumbre en la sociedad salvaje, Trad. ALIER, Barcelona: Ariel, 1982. PEÑA JUMPA, Antonio, "El poder judicial comunal aymara", en: PEÑA JUMPA, Antonio; CABEDO MALLOL, Vicente; LÓPEZ BÁRCENAS, Francisco, Constituciones, Derecho y Justicia en los pueblos indígenas de América, Lima: Fondo Editorial PUCP, 2002, pp. 362 y ss. 
Polít. crim. Vol. 12, No 23 (Julio 2017), Art. 4, pp. 103-123.

[http://www.politicacriminal.cl/Vol_12/n_23/Vol12N23A4.pdf]

juzgador tenía prestigio o auctoritas ${ }^{18}$ o simplemente poder fáctico, tampoco lo sabemos ni probablemente lo sabremos. En lo que conocemos hasta ahora de la historia remota existen ejemplos de todas esas hipótesis.

Pero ello no importa para el reconocimiento de esa finalidad principal: el proceso es un mecanismo de evitación de la autotutela. Pero no se dice por qué se quiere evitar la autotutela, que sería lo lógico y lo que nos interesaría a los efectos de la construcción del sistema integral. Se da por obvio que la venganza, el tomarse la justicia por propia mano, genera muchos más conflictos, de manera que la sociedad se hace irrespirable. El inconveniente consiste en que es probable que la preservación de nuestro sistema de convivencia no sea una finalidad exclusiva del Derecho penal, sino de todo el ordenamiento jurídico, lo que es, por cierto, muy fácilmente argumentable. Siendo así, la autotutela no sería más que una de las varias amenazas que existen a esa convivencia, probablemente una de las principales, pero en todo caso una más.

Además, no se puede dejar de lado que esa finalidad de evitación de autotutela, aunque posiblemente sea sólo un objetivo intermedio, encaja como un guante para explicar la finalidad de cualquier norma procesal. El objetivo de todas esas normas es favorecer la heterotutela, es decir, el trabajo de ese tercero, de manera que los ciudadanos no solamente no acudan, sino que no perciban la necesidad de acudir a la Selbsthilfe ${ }^{19}$. Para ello es fundamental la imparcialidad judicial, el derecho de defensa y la cosa juzgada. Lo veremos después.

Y con lo anterior podría darse el trabajo por acabado, ciertamente, al menos desde la perspectiva procesal. Sin embargo, conscientes probablemente de las carencias de la conclusión, los autores han ido bastante más allá, puesto que se han preguntado por el cometido de los principales conceptos procesales, más allá de la genérica evitación de la autotutela, lo que enlaza aún más con los estudios de la dogmática penal acerca de los fines del delito y la pena. Se analizará en los siguientes epígrafes.

\section{Finalidades de la jurisdicción.}

La jurisdicción es el concepto que explica la actividad del juez. Manuel Serra Domínguez elaboró una de las definiciones más claras y difícilmente controvertibles de la doctrina cuando afirmó que la jurisdicción es la determinación irrevocable del derecho en el caso concreto, seguida en su caso de su actuación práctica ${ }^{20}$. Se puede discutir cada palabra de esa definición, como se hará seguidamente, pero lo cierto es que ofrece una idea clara de lo que implica la jurisdicción: una declaración del juez con voluntad jurídica de imponerse.

La doctrina, italiana sobre todo, le dio bastantes vueltas al concepto, situándose fundamentalmente en torno a tres vértices, aunque en realidad, como veremos, se trataba de

\footnotetext{
18 CARRERAS LLANSANA, Jorge, "Las fronteras del Juez”, en: FENECH, Miguel; CARRERAS, Jorge, Estudios de Derecho Procesal, Barcelona: Bosch, 1962, pp. 103 y ss.

${ }^{19}$ ROSENBERG/SCHWAB/GOTTWALD, Zivilprozessrecht, cit. nota $\mathrm{n}^{\mathrm{o}}$ 8, p. 2.

${ }^{20}$ SERRA DOMÍNGUEZ, Jurisdicción, cit. nota $\mathrm{n}^{\circ} 15$, p. 50.
} 
NIEVA, Jordi. "Seis conceptos en busca de un objetivo: jurisdicción, acción, proceso, derechos, pena y delito".

uno solo. Las opciones son que el juez con su labor actúe derechos subjetivos ${ }^{21}$, o bien que actúe el derecho objetivo ${ }^{22}$, o bien que cree derecho ${ }^{23}$.

La opción subjetiva deja completamente al margen al Derecho penal precisamente, porque es una teoría pensada sobre todo en el derecho privado y en sus relaciones contractuales, en las que cada derecho va seguido de una obligación individual de cada parte. Pero no explica casi en absoluto qué hace un juez cuando trabaja con cualquier manifestación del Derecho público, salvo en parte el Derecho administrativo, en cuyo ámbito sí cabe hablar de derechos subjetivos de los ciudadanos.

Es por ello por lo que es descartable esta opción subjetiva, directamente conectada, como veremos, con la teoría concreta de la acción ${ }^{24}$. No da una respuesta única al papel de la jurisdicción en el ordenamiento jurídico. Como reacción a la misma, aunque también muy claramente como reacción a la Freierechtslehre ${ }^{25}$, surgió en Italia la teoría objetiva ${ }^{26}$, de forma menos irónica que el título de la Reine Rechtslehre de Kelsen ${ }^{27}$, que también reclamaba el papel del Derecho objetivo ${ }^{28}$. La misma defiende que el rol de la jurisdicción sería actuar el Derecho objetivo, intentando recuperar así el papel de los tribunales como cumplidores de la norma jurídica emanada del poder legislativo, el que representa la voluntad popular. De ese modo, el juez no puede ser un verso libre, sino que tiene que cumplir con los designios del legislador.

La teoría encaja perfectamente en cualquier ámbito del ordenamiento jurídico, incluido el Derecho penal, y por ello es defendida, expresa o tácitamente, por la mayoría de la doctrina, al llevar además la pátina de respeto de la división de poderes. Sin embargo, falla estrepitosamente en aquellos ámbitos en los que el ordenamiento jurídico carece de

\footnotetext{
${ }^{21}$ HELLWIG, Konrad, System des deutschen Zivilprozeßrechts, Darmstadt: Scientia Verlag Aalen, 1980, p. 2. "Dafür übernimmt der Staat die Pflicht, dem Privaten unter gewissen Voraussetzungen Rechtsschutz gegen gefährdung oder Verletzung seiner Privatrechtsstellung zu gewähren".

${ }_{22}$ CALAMANDREI, Piero, Instituciones de Derecho Procesal Civil, Vol. I, Trad. SENTÍS MELENDO, Santiago; Buenos Aires: Ediciones Jurídicas Europa-América, 1986, p. 202.

${ }^{23}$ SATTA, Salvatore; PUNZI, Carmine, Diritto Processuale Civile, Padova: CEDAM, 1996, p. 14. Lo cual ya había sido intuído por otros juristas, por ejemplo, CARNELUTTI, Francesco, "Nuove riflessioni sul giudizio giuridico", Rivista di diritto processuale civile, vol. 11, n 1 (1956), pp. 81-106, p. 104, "il giudizio non basta per fare la giustizia".

${ }^{24}$ WACH, Adolf, Manual de Derecho procesal Civil, Trad. BANZHAF, Buenos Aires: Ediciones Jurídicas Europa-América, 1977, p. 42.

${ }^{25}$ KANTOROWICZ, Hermann (Gnaeus Flavius), Der Kampf um die Rechtswissenschaft, Heidelberg: Winter, 1906.

${ }^{26}$ Nuevamente CALAMANDREI, Instituciones, cit. nota ${ }^{\circ}$ 22, p. 202.

${ }^{27}$ KELSEN, Hans, Reine Rechtslehre, ed. de Viena 1934, Darmstadt: Scientia Verlag Aalen, 1994.

${ }^{28}$ Ese papel, e incluso la ironía -rayana con la indignación- se desprende claramente de las primeras palabras de la obra de KELSEN, Reine Rechtslehre, cit. nota $\mathrm{n}^{\circ}$ 27, "Die Reine Rechtslehre ist eine Theorie des positiven Rechts. Des positiven Rechts schlechthin, nicht einer speziellen Rechtsordnung. Sie ist allgemeine Rechtslehre, nicht Interpretation besonderer nationaler oder internationaler Rechtsnormen. Als Theorie will sie ausschließlich, und allein ihren Gegenstand erkennen. Sie versucht, die Frage zu beantworten, was und wie das Recht ist, nicht aber die Frage, wie es sein oder gemacht werden soll. Sie ist Rechtswissenschaft, nicht aber Rechtspolitik."
} 
Polít. crim. Vol. 12, No 23 (Julio 2017), Art. 4, pp. 103-123.

[http://www.politicacriminal.cl/Vol_12/n_23/Vol12N23A4.pdf]

respuesta y recurre a la equidad o al simple buen criterio del juez ${ }^{29}$. Es algo parecido a lo que, por ejemplo, sucede en el ámbito penal cuando se delega en el juez un amplísimo margen, no siempre claramente motivado, en la determinación de la pena a imponer ${ }^{30}$. De hecho, ni siquiera el ordenamiento jurídico da razón de por qué un hecho delictivo es sancionado con una concreta pena, existiendo en este sentido una fenomenal imprecisión del legislador ${ }^{31}$, que por añadidura acaba recurriendo al juez para que establezca, casi intuitivamente, la pena concreta.

Pero pese a los esfuerzos de la teoría objetiva, en EEUU y en Italia acabaron surgiendo opciones que seguían, en el fondo y pese a sus diferencias, una idea base análoga de la Escuela del Derecho Libre. Tanto el realismo jurídico americano ${ }^{32}$ como SATTA $^{33}$ reconocen el papel creador del derecho del juez, surgiendo de este modo la opción creacionista de la jurisdicción. La misma parte de la base de que el legislador establece una serie de normas generales, el derecho objetivo. Pero esa vocación de abstracción no puede cubrir cada caso concreto que se plantea en la realidad, y por ello la labor del juez es fundamental en la determinación del derecho en ese caso concreto, lo que lleva a esta opción a argumentar que esa determinación no sería una simple adaptación hermenéutica del derecho objetivo, sino una auténtica creación de la norma jurídica ${ }^{34}$, aunque sin esa vocación de generalidad del derecho objetivo.

No obstante, la teoría se refuerza al contemplar el papel creador del derecho de la jurisprudencia, incluso con vocación de generalidad, lo que es especialmente claro en el mundo anglosajón, pero que también se observa en el resto de tribunales cuando fuerzan una interpretación legal o incluso crean una solución para una multitud de casos concretos. Puede gustar más o menos, pero en esos casos se están creando normas jurídicas ${ }^{35}$. Sucede también en el reino del principio de legalidad: el Derecho penal. El Tribunal Supremo, tomando el precepto del legislador, va estableciendo -o concretando- los elementos objetivos y subjetivos de los tipos penales, de manera que se restringe o se amplía el ámbito de la tipificación, como ha ocurrido en diversos supuestos como el del delito de prevaricación (art. 446 C.P.) ${ }^{36}$ o el de desobediencia (art. 556 C.P.) $)^{37}$. Aunque probablemente no debiera ser así, no hay otro remedio que acudir a la jurisprudencia para saber si el hecho es realmente delictivo.

Puede parecer que todas estas teorías, y otras intermedias, no sirven, sin embargo, para la construcción de ese sistema integral, porque se centran en averiguar qué hace el juez, y no

\footnotetext{
${ }^{29}$ Pese a los denodados esfuerzos de CALAMANDREI, Instituciones, cit. nota $\mathrm{n}^{\mathbf{o}}$ 22, p. 202, por evitar esa crítica.

${ }^{30}$ MIR PUIG, Derecho penal, cit. nota $\mathrm{n}^{\circ} 1$, pp. 745 y ss.

${ }^{31}$ WESEL, Uwe, Fast alles, was Recht ist, München: C.H. Beck, 1994, p. 192.

${ }^{32}$ LLEWELLYN, Karl N., Jurisprudence. Realism in Theory and Practice, New Brunswick: Transaction Publishers, 2008, pp. 4, 17-18.

${ }^{33}$ SATTA, Diritto Processuale Civile, cit. nota $\mathrm{n}^{\mathrm{o}} 23, \mathrm{p} .16$.

${ }^{34}$ Lo reconoce hasta KELSEN, Reine Rechtslehre, cit. nota $n^{\circ} 27$, p. 79. "Die Funktion der sogenannten Rechtsprechung ist vielmehr konstitutiv, ist Rechtserzeugung im eigentlichen Sinne des Wortes."

${ }^{35}$ Nuevamente KELSEN, Reine Rechtslehre, cit. nota n ${ }^{\circ} 27$, p. 79.

${ }^{36}$ Sentencia Tribunal Supremo 228/2015, de 21 de abril de 2015, FD 3.

${ }^{37}$ Sentencia Tribunal Supremo 800/2014, de 12 de noviembre de 2014, FD 8.
} 
NIEVA, Jordi. "Seis conceptos en busca de un objetivo: jurisdicción, acción, proceso, derechos, pena y delito".

por qué lo hace. Sin embargo, no es enteramente así. La opción subjetiva permite afirmar que el juez contribuye a la materialización de uno de los fines principales de varios sectores del ordenamiento: el cumplimiento de derechos subjetivos, lo que le da una vocación de generalidad. Con la opción objetiva sucede algo parecido. El juez ejecuta y hace cumplir la obra del legislador, producto principal del ordenamiento, papel que aparece decididamente reforzado con la opción creacionista, puesto que desde ese punto de vista el juez le daría la misma vida al ordenamiento jurídico, que no sería sino una voz apagada, como decía Salvatore $\mathrm{Satta}^{38}$, de no tener a alguien que le ayudara a pronunciar sus palabras.

Se podría llegar a concebir que el Derecho penal sigue un fin similar, dado que en el fondo sanciona a aquel que se aparta gravemente de dicho ordenamiento ${ }^{39}$, dejándolo inservible. De ese modo, el Derecho procesal daría vida al ordenamiento, mientras que el Derecho penal evitaría que se le diera muerte.

La opción sería bastante original y hasta cierto punto integral, pero ignoraría que es difícil explicar que una parte del mismo ordenamiento es la que le da la vida al propio ordenamiento, o simplemente la conserva. Se podría acudir a una comparación con el cuerpo humano y sus órganos y miembros, en el que algunos permiten a la persona realizar actos materiales, como las manos, mientras que otros mantienen al sujeto con vida, como el corazón, el hígado o el cerebro.

Sin embargo, por sugestiva que parezca la metáfora, resulta, además, incompleta, puesto que deja al resto de ramas del derecho en un papel incomprensiblemente secundario ${ }^{40}$, siendo que casi todas ellas también contribuyen a la evitación de conflictos y, por tanto, a la preservación del orden social. Ello resulta especialmente claro con el Derecho civil ${ }^{41}$, e incluso más con el Derecho administrativo y su omnipresente visión del interés general ${ }^{42}$.

Por tanto, no encontramos, con el estudio de la jurisdicción, ese objetivo que singularice al Derecho penal y al Derecho procesal penal como partes de un mismo ámbito del ordenamiento jurídico que comparten una finalidad. En consecuencia, es preciso seguir buscando.

\footnotetext{
${ }^{38}$ SATTA / PUNZI, Diritto Processuale Civile, cit. nota ${ }^{\circ} 23$, p. 14.

${ }^{39}$ Cfr. MIR PUIG, Derecho penal, cit. nota n ${ }^{\circ} 1$, pp. 39-40.

${ }^{40}$ MIR PUIG, Derecho penal, cit. nota $\mathrm{n}^{\circ} 1$, pp. 40 y 41 , se refiere a otro sector del ordenamiento con el mismo fin: el Derecho administrativo sancionador.

${ }^{41}$ Muy claramente ALBALADEJO, Manuel, Derecho Civil I, Vol. I, Barcelona: Bosch, 1985, p. 41. Cfr. LACRUZ BERDEJO, José Luis, Elementos de Derecho Civil I, Parte General, Vol. I, Madrid: Dykinson, 2002, p. 33.

42 GARCÍA DE ENTERRÍA, Eduardo; FERNÁNDEZ, Tomás Ramón, Curso de Derecho Administrativo, I, Madrid: Civitas, 1992, p. 43.
} 
Polít. crim. Vol. 12, No 23 (Julio 2017), Art. 4, pp. 103-123.

[http://www.politicacriminal.cl/Vol_12/n_23/Vol12N23A4.pdf]

\section{Finalidades de la acción.}

Es posible que esa común finalidad surja, al menos en parte, de un estudio notoriamente infructuoso: el del supuesto concepto de acción ${ }^{43}$. Si ello fuera así, por fin habrían tenido una finalidad, aunque inconsciente, una suma de doctrinas baldías.

El estudio del concepto se inició en Prusia con F.K. von Savigny ${ }^{44}$, que recuperó para el Derecho actual una noción que, en realidad, sólo tenía sentido en el antiguo proceso formulario romano: la actio. Y de ese modo, dijo que la acción sería el derecho a la protección judicial que surge de la violación de un derecho ${ }^{45}$, subjetivo, se entiende, puesto que el autor centraba sus conclusiones en el Derecho civil. Así definió von Savigny la acción en sentido material, puesto que en sentido formal la acción era la simple presentación de la demanda, y era el concepto entendido en tal sentido el único que encomendaba al Derecho procesal ${ }^{46}$.

A partir de ahí, la doctrina mayoritariamente se enzarzó en un debate inútil sobre si la acción era independiente o no del derecho material, o bien si debía obedecer a la primera orientación de von Savigny (teoría concreta) ${ }^{47}$ o a la segunda (teoría abstracta) ${ }^{48}$. El debate, como es fácil deducir, no llevaba a ninguna parte.

Pero sin embargo, la definición de von Savigny, aún enfocada en el Derecho civil, nos dice entre líneas algo útil para los efectos ahora considerados: el Derecho procesal se pone en marcha cuando se viola el Derecho material, o simplemente se alega esa violación. Por tanto, desde esta perspectiva en cualquiera de las opciones doctrinales, el Derecho procesal sería, nuevamente, el agente protector del ordenamiento jurídico, desempeñando así una función tutelar.

Pero esa conclusión nos devuelve a los problemas anunciados en el epígrafe anterior: una parte de lo tutelado tutelaría lo tutelado, lo que no es más que una cacofónica tautología. Con esta opción, sin embargo, el Derecho procesal ya no daría vida al ordenamiento, sino que simplemente evitaría que muriera, lo que ya es coincidente con el fin del Derecho penal, abriéndose así la puerta a la constitución de ese sistema integral. De ese modo, Derecho penal y Derecho procesal se encargarían de lo mismo: de la protección del ordenamiento y desde la misma perspectiva.

\footnotetext{
43 Personalmente he renunciado a incluir esta confusa e inconducente noción entre los conceptos fundamentales del Derecho procesal. Expongo las razones en NIEVA FENOLL, Jordi, "Imprecisiones privatistas de la ciencia jurisdiccional”, en: EL MISMO, Jurisdicción y proceso, Madrid: Marcial Pons, 2009, pp. 19 y ss.

${ }^{44}$ VON SAVIGNY, Friedrich Karl, System des heutigen römischen Rechts, Vol. 6, Darmstadt: Scientia Verlag Aalen, 1974, p. 3.

${ }^{45}$ VON SAVIGNY, System, cit. nota $\mathrm{n}^{\circ} 44$, p. 5.

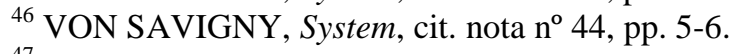

${ }^{47}$ WACH, Adolf, Handbuch des deutschen Zivilprozeßrecht, Leipzig: Verlag von Duncker \& Humblot, 1885, pp. 21-22.

${ }^{48}$ PLÓSZ, Alexander, Beiträge zur Theorie des Klagerechts, Leipzig: Verlag von Duncker \& Humblot, 1880, p. 4. DEGENKOLB, Heinrich, Einlassungszwang und Urteilsnorm. Beiträge zur materiellen Theorie der Klagen insbesondere der Anerkennungsklagen, Leipzig: Breitkopf \& Härtel, 1877 p. 1.
} 
NIEVA, Jordi. "Seis conceptos en busca de un objetivo: jurisdicción, acción, proceso, derechos, pena y delito".

No obstante, no se gana absolutamente nada suprimiendo el potencial creador del Derecho Procesal, a cambio de integrarlo en una función que, nuevamente, puede ser de todo el ordenamiento jurídico y no exclusivamente del Derecho penal o del Derecho procesal. Por tanto, esta opción, aunque consigue el fin de la integralidad, nos devuelve a un camino sin salida.

\section{Finalidades del proceso y del juicio jurisdiccional.}

También se ha teorizado sobre el concepto de proceso. Los autores, intentando llenar de contenido jurídico un concepto que en buena medida bascula entre lo vulgar y lo cotidiano, compararon el proceso con un contrato ${ }^{49}$, con un cuasicontrato ${ }^{50}$, con una relación jurídica ${ }^{51}$ o incluso con un conjunto de "situaciones jurídicas" 52 , o incluso lo redujeron a mero procedimiento $^{53}$, confundiendo así ambas nociones. Pero finalmente, la opción que parece haber triunfado es la que no intenta comparar al proceso con nada, sino que sencillamente describe que es una sucesión de actos que tiene por finalidad emitir un juicio jurisdiccional $^{54}$. Tan simple como eso.

Con ello, el estudio nos aboca a un concepto diferente: el de juicio. Su definición no es controvertida, en el sentido de que se trata de la decisión del juez, aunque sí que se discute sobre su naturaleza ${ }^{55}$. Pero ese estudio, aún siendo sin duda el más interesante y fructífero, no aporta nada desde la perspectiva que estamos considerando en este trabajo, por lo que no será tratado.

Pero sí cabe hacerse una pregunta que la doctrina pocas veces se ha formulado, y que daría respuesta a la cuestión del sistema integral: ¿para qué existe el juicio? Y es que justamente esta formulación sería probablemente más correcta que preguntarse para qué existe el Derecho procesal. Ya hemos visto que el Derecho procesal combate la autotutela, y que posibilita la emisión del juicio jurisdiccional. Ahora bien, ¿existe el juicio jurisdiccional simplemente para conjurar la autotutela? ¿O más bien cabría decir que el juicio jurisdiccional, como producto de la jurisdicción, persigue la determinación -o creación- del derecho en el caso concreto? Y si así fuera, ¿son ambas cosas incompatibles?

Desde la perspectiva del Derecho penal y su estricto principio de legalidad, en el proceso penal el derecho no se crea salvo en los casos antes referidos de indeterminación de la norma, en los que esa creación/determinación se hace inevitable, por lo que esa opción definitoria de la finalidad del juicio se hace difícil de mantener a ultranza. Pero sin embargo, sí queda subsistente la opción de la evitación de autotutela. Y es que esa

\footnotetext{
${ }^{49}$ DÉMOLOMBE, Cours de Code, cit. nota n ${ }^{\text {o }}$ 10, p. 179

${ }^{50}$ DE GUENYVEAU, Arnault, Du quasi contrat judiciaire, cit. nota no 10, pp. 13-14.

${ }^{51}$ VON BÜLOW, Oskar, Die Lehre von den Proceßeinreden und die Proceßvoraussetzungen, Gießen: Emil Roth, 1868, p. 1-2.

${ }^{52}$ GOLDSCHMIDT, James, Zivilprozeßrecht, Berlin: Springer, 1929, p. 4.

${ }^{53}$ FURNO, Carlo, "Intervento del prof. Carlo Furno, straord. dell' Università di Perugia", en: AAVV, Atti del Congreso internazionale di diritto processuale civile, Padova: CEDAM, 1953, pp. 110-112.

${ }^{54}$ Hay referentes más modernos, pero el origen -no identificado- de esta definición está en PLÓSZ, Beiträge $z u r$, cit. nota $\mathrm{n}^{\mathrm{o}}$ 48, p. 3 e incluso en VON BÜLOW, Die Lehre, cit. nota $\mathrm{n}^{\mathrm{o}}$ 51, p. 4.

${ }^{55}$ Por todos, DE MARINI, Carlo Maria, Il giudizio di equità nel processo civile, Padova: CEDAM, 1959.
} 
Polít. crim. Vol. 12, No 23 (Julio 2017), Art. 4, pp. 103-123.

[http://www.politicacriminal.cl/Vol_12/n_23/Vol12N23A4.pdf]

finalidad, más que del Derecho procesal, es de su producto más preciado, sin el que el mismo carecería de todo sentido: el juicio. Todo en el Derecho procesal está enfocado a emitir ese juicio, desde las mismas normas de procedimiento en sí mismas, pasando por las medidas cautelares o la prueba. Las normas de ejecución sirven para que el juicio sea eficaz, pero por ello no se separan de esa común finalidad. Hasta los derechos fundamentales procesales, antiguos principios $^{56}$, sirven, como veremos, fundamentalmente a la correcta emisión del juicio.

Y el juicio es el producto de llamar a un tercero para que decida entre al menos dos partes que no han sido capaces de llegar a una transacción, para evitar que el enfrentamiento degenere en violencia. Ello, como se ha dicho, parece cuadrar bien con el Derecho penal, pero ha llegado el momento de decir que sólo en parte. En un delito de robo, por ejemplo, el Juez se sitúa entre quien robó y la persona a quien robaron, para evitar que el segundo quiera eliminar al primero, o simplemente recobrar por la fuerza lo robado, generando violencia.

Pero en otros muchos delitos no se da esa dualidad de sujetos. En un homicidio de un sujeto sin familia ni amigos, no hay peligro de que nadie quiera vengarlo. Pero lo mismo sucede en un delito de desobediencia, o de conducción bajo los efectos del alcohol sin resultado de muerte o lesiones (art. 379 C.P.). Y aún y así, en esos casos en los que en realidad no hay conflicto, se requiere la presencia del juez y el consiguiente juicio jurisdiccional. ¿Por qué?

Formulo esta pregunta, que puede parecer inconducente, porque en su respuesta está, en mi opinión, la clave de ese sistema integral. Se ha dicho hasta el momento que el Derecho penal necesita al juez para ser efectivo, pero no se ha explicado por qué. En realidad, el Estado podría imponer penas sin contar con los jueces. Históricamente lo ha hecho muchísimas veces y lo sigue haciendo. Pero entonces, ¿por qué se reclama la presencia del juez? Su presencia se hace imprescindible incluso en Estados dictatoriales, y no es simplemente para aparentar limpieza en el sistema, ni mucho menos.

La razón es intrigante, pero finalmente ofrece una respuesta clara a la constitución del sistema integral del Derecho penal, aunque más bien cabría decir del sistema punitivo, a fin de no escorar científicamente en la apariencia lo que en la esencia no es sólo Derecho penal. Esa respuesta merece un epígrafe aparte.

\section{El juez resulta imprescindible... ¿para qué?}

Nuevamente tenemos que echar una brevísima mirada a la historia. A lo largo de la misma, como se vio, ha existido el juez-comunidad -la asamblea plenaria del núcleo humano-, el juez colectivo representante -el jurado- y el juez unipersonal ${ }^{57}$. Pero con justicia o sin ella, casi siempre ha habido algo parecido a un juez, pese a que han existido épocas y momentos en que han sido suprimidos, como ya se dijo. Es decir, ese tercero parece antropológicamente omnipresente. ¿Por qué?

\footnotetext{
${ }^{56}$ NIEVA FENOLL, Derecho Procesal, cit. nota n ${ }^{\circ} 12$, pp. 122 y ss.

${ }^{57}$ Ver esta evolución en NIEVA FENOLL, Jordi, "Ideología y justicia legal (con una hipótesis sobre el origen romano del jurado inglés)", Revista Ius et Praxis, n 1 (2016), año 22, pp. 59-86.
} 
NIEVA, Jordi. "Seis conceptos en busca de un objetivo: jurisdicción, acción, proceso, derechos, pena y delito".

La razón es plenamente coincidente con la esencia generadora del proceso penal. Aunque los pueblos muchas veces eligen líderes, o bien permiten más o menos voluntariamente que se impongan, lo cierto es que la convivencia social es fruto de un consenso expreso o tácito entre los que deciden ser vecinos. Cuando ocurre algo que los vecinos rechazan ${ }^{58}$, ese consenso generará la idea de querer averiguar la real existencia de ese algo, pero precisamente porque lo rechazan.

Como es sabido, el Derecho penal es probablemente el Derecho que es o debiera ser fruto de un mayor consenso ${ }^{59}$, de manera que cuando lo sancionado no goza de aceptación social, el sistema entra en crisis si la fuerza de influencia de la norma sobre la opinio iuris no acaba por generar artificialmente ese consenso. Pero por un camino u otro, el consenso, como se ve, acaba teniendo relevancia prácticamente siempre.

Pues bien, a fin de expresar ese consenso en su máxima y más dura expresión, la sancionadora, los miembros de la comunidad deben buscar también ese consenso. Es posible que se genere ese consenso de manera espontánea, o más estructurada democráticamente, o bien que confíen plenamente en su líder, y junto a la labor de legislar y gobernar, le atribuyan también el poder de juzgar, más o menos voluntariamente. Pero incluso en este último caso, lo habitual es que existan jueces que, pese a poder ser de la confianza del líder, en puridad debieran ser de la confianza de la comunidad.

Y es que el Derecho penal es -o debiera ser en democracia- fruto de un consenso social sobre aquello que más se odia. Pues bien, la presencia del juez no es más que la necesidad de expresar en lo concreto ese consenso social. Porque una cosa es regular aquello que está castigado, y otra castigarlo efectivamente. En épocas remotas, el pueblo condenaba al reo a la exclusión, es decir, al destierro, y cuando ni siquiera eso les parecía suficiente, lo mataban. Pero se requería siempre ese consenso popular, al menos en comunidades pequeñas sin líderes claros que celebraban procesos asamblearios. De hecho, por las dificultades de hallar en ocasiones ese consenso se acudía al bestialismo de la ordalía ${ }^{60}$, que igualmente gozaba de consenso por su enorme aceptación social fruto de la superchería ${ }^{61}$.

En consecuencia, el Derecho penal sería la plasmación ex ante de ese consenso. El Derecho procesal, la plasmación ex post. Pero ese consenso siempre está presente. Está ahí en los lugares democráticos, pero también en las dictadoras inducidas por la propia población, en las que la pereza mental de los habitantes provoca la aparición de reyezuelos de poder omnímodo que se aprovechan de esa abulia o temor ciudadanos en la labor de gobernar. Como ya se dijo, en las dictaduras impuestas, en realidad todo el sistema punitivo es pura apariencia. No existe el consenso, pero se anhela aparentarlo, porque los ciudadanos desean, pese a todo, que existan los jueces. Porque creen que en ellos verán reflejadas sus opiniones, es decir, su idea de lo justo. De ahí la visible incomprensión y frustración social

\footnotetext{
58 “...determinados comportamientos sociales que se reputan indeseables”, dice MIR PUIG, Derecho penal, cit. $\operatorname{nota~}^{\circ} 1$, p. 39.

${ }^{59}$ GREEN, Stuart, Mentir, hacer trampas y apropiarse de lo ajeno, Madrid: Marcial Pons, 2013, pp. 337 y ss.

${ }^{60}$ PATETTA, Federico, Le ordalie, Torino: Fratelli Bocca Editori, 1890, pp. 3 y ss.

${ }^{61}$ FOUCAULT, Michel, La verdad y las formas jurídicas, Trad. LYNCH, Barcelona: Gedisa, 1996, pp. 6162.
} 
Polít. crim. Vol. 12, No 23 (Julio 2017), Art. 4, pp. 103-123.

[http://www.politicacriminal.cl/Vol_12/n_23/Vol12N23A4.pdf]

que se produce cuando, eventualmente, el juez no decide según lo que pensaban los ciudadanos, sino según la prueba que ha observado y lo que le ordena el Derecho penal, es decir, correctamente. A pesar de lo acertado del proceder judicial los ciudadanos sienten, sin saberlo, que se ha roto el consenso, que es la principal fuente generadora de su idea de justicia.

En realidad, todo en sociedad parte de ese consenso. La regla de convivencia básica es, como ha descrito la Psicología, "haz lo mismo que todos, y todo irá bien" ${ }^{62}$. Se vuelve, por tanto, a la idea del consenso expreso, tácito o forzado, pero consenso al fin. Esa es, en realidad, la justicia, que fundamentalmente es lo que a los ciudadanos de una comunidad les parece justo en un momento dado, aunque a otros observadores no nos lo parezca. Y el llamado a aplicarla es el mismo pueblo, si es pequeño, y cuando ello es demográficamente imposible aparecen los jueces, como sujetos encargados de la expresión de ese consenso.

En consecuencia, Derecho penal y Derecho procesal penal por fin confluyen. Son sectores del ordenamiento que reflejan con mucha claridad -bastante más que el resto- la existencia de esos consensos sociales. De ahí que los Derechos penal y procesal lleguen a un mismo fin y estén condenados a entenderse.

Resumiendo todo lo anterior en una frase breve: la finalidad de Derecho penal y del Derecho procesal es exactamente la misma: la generación y custodia del consenso social. El primero como respetada rama del Derecho que estudia el sector del ordenamiento de la "ultima ratio" y que explica el consenso social y lo racionaliza. El segundo hace efectivo dicho consenso, recreándolo en el caso concreto. Pero para ello es necesario que el juez esté en las mejores condiciones de recoger ese consenso, ayudando a esa misma racionalización a través de la aplicación de otro sector clave del ordenamiento: los derechos fundamentales. Ahí es donde el estudio de los principios procesales y, como digo, la protección de los derechos fundamentales, desempeñan un papel absolutamente vital, sólo incidentalmente destacado por la doctrina. Lo veremos en el siguiente epígrafe.

\section{El papel de los derechos fundamentales y los antiguos principios procesales en el correcto desempeño de la función judicial.}

Los derechos fundamentales existen como barrera de los ciudadanos para defenderse del omnímodo poder del Estado. Ello está suficientemente demostrado y no es preciso insistir en ello. Basta recordar que las declaraciones de derechos más importantes se han desarrollado como reacción a poderes injustos: la Bill of Rights inglesa de 1689 se promulgó tras la Revolución Gloriosa de 1688, que eliminó el poder absoluto del rey en favor del parlamentarismo. La Declaración de Virginia de 1776 fue la antesala de la Declaración de Independencia de los EEUU. La Declaración de los Derechos del Hombre y del Ciudadano llega en 1789, tras la Revolución Francesa, que liquida la monarquía absoluta y el feudalismo. Y la Declaración Universal de los Derechos Humanos sobreviene en 1948, es decir, poco después de la derrota de terribles totalitarismos en la II Guerra Mundial.

${ }^{62}$ GIGERENZER, Gerd, Decisiones intuitivas, Barcelona: Ariel, 2008, p. 212 
NIEVA, Jordi. "Seis conceptos en busca de un objetivo: jurisdicción, acción, proceso, derechos, pena y delito".

Sin embargo, en materia procesal poseen una finalidad adicional. Simplificando al máximo esos derechos, cabe decir que consisten básicamente en una trilogía: imparcialidad, defensa y cosa juzgada ${ }^{63}$. Pues bien, sobre todo los dos primeros derechos están enfocados a que la función judicial pueda prestarse con excelencia, de manera que el juez pueda captar debidamente el consenso antes citado, de manera que dicte una sentencia que los ciudadanos perciban como justa, o bien que deba serlo porque se ajusta al ordenamiento jurídico, que es o debe ser fruto de otro consenso, lo que es -o debiera ser- especialmente evidente en materia penal.

A fin de realizar su labor con pulcritud, el juez debe averiguar también correctamente la realidad. Mala aplicación de la ley sería la que se realizara sobre un supuesto de hecho falso. Pues bien, los derechos fundamentales contribuyen a guiarle y darle algunos apoyos para que no se desvíe del camino. Para entenderlo, hay que tener en cuenta que el juicio jurisdiccional, esencialmente, es una decisión del juez. Y como argumenta la psicología cognitiva, cualquier decisión suele estar basada en heurísticos que pueden provocar sesgos, que son los que llevarán al juez a una decisión errónea ${ }^{64}$.

Es por ello por lo que se exige que el juez sea imparcial, a fin de aislarle de sus emociones sobre el asunto o las partes, que pueden hacerle entrar en el peligroso heurístico de afección $^{65}$. Igualmente se le exige que respete el derecho a la defensa, a fin de que en las diferentes fases del proceso tenga en cuenta lo que aleguen las partes, y no únicamente su propia opinión. En realidad es exactamente lo mismo que apuntaron glosadores y autores posteriores cuando le decían que juzgara secundum allegata et probata-partium-et non secundum constientiam suam ${ }^{66}$. Justamente ese brocardo dio origen al principio dispositivo, y más exactamente al principio de aportación de parte ${ }^{67}$. Con estos principios, fundamentales y origen de casi todos los demás que después describió la doctrina, lo que se pretendía es que el juez escuchara a las partes, es decir, que permitiera su defensa, lo que no ocurre cuando se hace un uso abusivo de los principios de oficialidad e inquisitivo, que llevados a ultranza suponen la denegación de la defensa y el consiguiente aislamiento del juez en su propio criterio, lo que está muy bien descrito por los sesgos egocéntrico ${ }^{68}$ y de confirmación ${ }^{69}$. Con los mismos, el juez cree que todo el mundo es de su opinión, y además

\footnotetext{
${ }^{63}$ Lo explico en NIEVA FENOLL, Derecho procesal, cit. nota $\mathrm{n}^{\circ} 12$, pp. 125 y ss.

${ }^{64}$ KAHNEMAN, Daniel; SLOVIC, Paul; TVERSKY, Amos, Judgment under Uncertainty: Heuristics and Biases, Cambridge: Cambridge University Press, 1982, passim.

${ }^{65}$ FINUCANE, Melissa; ALHAKAMI, Ali; SLOVIC, Paul; JOHNSON, Stephen M., "The Affect Heuristic in Judgment of Risks and Benefits", Journal of Behavioral Decision Making, vol. 13, n 1 (2000), pp. 1-17. SLOVIC, Paul; FINUCANE, Melissa; PETERS, Ellen; MacGREGOR, Donald, "Risk as Analysis and Risk as Feelings: Some Thoughts about Affect, Reason, Risk, and Rationality", Risk Analysis, vol. 24, n 2 (2004), pp. 311-322.

${ }^{66}$ Nuevamente ACCURSIUS, Corporis Iustinianaei, cit. nota $\mathrm{n}^{\mathrm{o}}$ 11, p. 17: "Iudex debet ferre sententiam, secundum allegata et probata, non secundum conscientiam".

${ }^{67}$ NIEVA FENOLL, Jordi, "La cattiva reputazione del principio inquisitorio", Rivista trimestrale di diritto e procedura civile, vol. 68, n 3 (2014), pp. 943-970.

${ }^{68}$ ARTIETA PINEDO, Isabel; GONZÁLEZ LABRA, María José, “La toma de decisiones”, en: GONZÁLEZ LABRA, María José, Introducción a la psicología del pensamiento, Madrid: Trotta, 2005, pp. 344.

${ }^{69}$ MYERS, David G., Intuición. El poder y el peligro del sexto sentido, Trad. SOLANA, Guillermo, Barcelona: Paidós, 2003, p. 175.
} 
Polít. crim. Vol. 12, No 23 (Julio 2017), Art. 4, pp. 103-123.

[http://www.politicacriminal.cl/Vol_12/n_23/Vol12N23A4.pdf]

no solamente no la cambia, sino que reinterpreta erróneamente todas las informaciones que recibe en apoyo de su tesis, aunque rectamente le deberían llevar a un cambio de opinión.

Por consiguiente, ignorando la imparcialidad y la defensa, el juez ignora el consenso social y se forma una idea equivocada del existente. No escucha a las partes, fuentes informadoras principales del consenso en el proceso, o al menos de sus posibles versiones, dado que las mismas deben ser completadas con lo que declara el ordenamiento, naturalmente. Y de ese modo, el único "consenso" que tiene en cuenta el juez es el que está en su mente. Es decir, lo que debiera ser una decisión de la comunidad, se convierte en la decisión individual de un falso representante.

De ese modo, también desde la teoría general de los derechos fundamentales, e incluso de la más antigua de los principios, se comprueba que la orientación del consenso es correcta. Por fin, más allá de la evitación de la autotutela o del mantenimiento de un estilo de convivencia, se llega a la conclusión de que un sistema integral punitivo debe regirse por la idea única de consenso. Del consenso para elaborar los tipos penales se encarga el Derecho penal. De su correcta plasmación en el juicio jurisdiccional se encarga el Derecho procesal. Ambos son imprescindibles recíprocamente. Sin juicio, el Derecho penal es letra muerta. Sin Derecho penal, las posibilidades de elaboración de un falso consenso se multiplicarían. Aunque la mente judicial esté debidamente informada por las partes y por su propia formación esté en condiciones de emitir un juicio correcto, sin esa guía que supone el Derecho penal, en comunidades relativamente complejas se disgregaría absolutamente el sentido de lo justo, dado que cuanto más numerosa es esa comunidad, mayores discrepancias pueden surgir, especialmente en un aspecto tan sensible como aquello que más rechaza una sociedad. Se perdería, en definitiva, una idea coherente de lo justo, lo que quebraría finalmente la supervivencia del grupo, surgiendo la autotutela y rompiéndose la convivencia. De ahí la necesidad de existencia de la norma penal uniforme y de un juez que la aplique y, eventualmente, la complete en las mejores condiciones.

\section{Las instituciones procesales y su interacción con el Derecho penal.}

Descubierto, por tanto, ese fin único de ambas ramas del Derecho, resta solamente pronunciarse por las supuestas interacciones -o interferencias- que ha denunciado la doctrina $^{70}$. Me centraré sobre todo en el sobreseimiento, la prueba y la presunción de inocencia como aspectos comunes a cualquier ordenamiento jurídico.

En cuanto al sobreseimiento, en absoluto puede observarse como una barrera al Derecho penal. Los hechos dejan de perseguirse cuando la ley penal no los tipifica como delito, o bien cuando esa misma ley prevé causas de inimputabilidad que hacen imposible la sanción $^{71}$. Nada de ello es obstáculo, sino mera ejecución procesal de lo que dice el Derecho sustantivo.

\footnotetext{
${ }^{70}$ WOLTER, Estudio, cit. nota n ${ }^{\circ} 7$, pp. 31 y ss.

${ }^{71}$ Ver, por ejemplo, el art. 637 de la Ley de Enjuiciamiento Criminal española o el art. 177 del CPP francés.
} 
NIEVA, Jordi. "Seis conceptos en busca de un objetivo: jurisdicción, acción, proceso, derechos, pena y delito".

Más dudas pueden surgir en los supuestos de sobreseimiento por no existir evidencias suficientes para juzgarlo ${ }^{72}$, lo que enlaza con la cuestión de la prueba. Sin embargo, tampoco ese sobreseimiento, libre o provisional, constituye obstáculo alguno a la norma penal. Bien al contrario, cumple plenamente con un principio orientador, convertido por algunas constituciones incluso en derecho fundamental, y que constituye la clave de bóveda esencial de todo el sistema: la presunción de inocencia, que desde luego puede citarse en su más antigua acepción de in dubio pro reo. Actualmente ya no existen dudas de que ambos principios son exactamente el mismo ${ }^{73}$. Pero más allá de eso, fijémonos que con la presunción de inocencia de lo que se trata es de eliminar de la mente judicial un consenso social especialmente nocivo: el prejuicio social de culpabilidad, extendidísimo en cualquier latitud del mundo ${ }^{74}$.

Pues bien, si se pudieran llevar adelante procesos que solamente están basados en conjeturas, en hipótesis que pueden tener confirmación simplemente intuitiva, pero en ningún caso empírica, la presunción de inocencia no estaría siendo respetada. Se estaría perjudicando al reo con una pena de banquillo, una incertidumbre y la consiguiente desazón que sólo serviría para dañarle innecesariamente, y quizás para satisfacer el ánimo inquisitorio de algunos de los sujetos del proceso, así como de ciudadanos tan paranoicos como dichos sujetos. Si utilizados todos los esfuerzos del fenomenal aparato investigador del Estado resulta que no se descubren evidencias suficientes de un hecho, el mismo debe dejar de ser perseguido, porque de lo contrario la presunción de inocencia sería irremediablemente vulnerada, lo que resulta absurdo desde el punto de vista de la misma esencia de la norma penal.

En consecuencia, esas interacciones entre el proceso y el Derecho sustantivo no se traducen, en absoluto, en interferencias, sino que sólo son piezas de un mismo sistema, ese sistema integral del que, en conclusión, se hablará en el último epígrafe. Sí son interferencias, en cambio, y como ya se advirtió, las generosas posibilidades de renuncia a la acción penal del ministerio fiscal alemán. Dejar de perseguir hechos porque el delincuente sea joven puede estar justificado, no sólo por razones de política criminal, sino por evidencias neurocientíficas ${ }^{75}$. No hacerlo por motivos políticos es simplemente un fraude al consenso social del que venimos hablando.

\section{8. ¿Es posible un sistema integral del Derecho penal?}

No sólo es posible ese sistema integral, sino que resulta totalmente ineludible. Es probable que algunas disposiciones legislativas puntuales hayan podido resultar sorprendentes a ese fin, pero finalmente parece completamente claro que siendo el proceso el cauce a través del cual se actúa el Derecho penal, no pueden existir incoherencias entre uno y otro.

\footnotetext{
${ }^{72}$ Art. 641 Ley de Enjuiciamiento Criminal, que provoca un sobreseimiento provisional. En Alemania, en cambio, en estos casos el sobreseimiento es libre ( $\$ 203$ StPO).

${ }^{73}$ Lo explico en NIEVA FENOLL, Jordi, La duda en el proceso penal, Madrid: Marcial Pons, 2013, pp. 62 y ss.

${ }^{74}$ NIEVA FENOLL, La duda, cit. nota $\mathrm{n}^{\mathrm{o}} 73$, p. 102.

75 POZUELO PÉREZ, Laura, "Sobre la responsabilidad penal de un cerebro adolescente", InDret, $\mathrm{n}^{\circ} 2$ (2015), pp. 1 y ss.
} 
Polít. crim. Vol. 12, No 23 (Julio 2017), Art. 4, pp. 103-123.

[http://www.politicacriminal.cl/Vol_12/n_23/Vol12N23A4.pdf]

De ese modo, teniendo claro el objetivo común de ambos derechos -la averiguación del consenso social en torno a lo más rechazado-, como ya se anunció, se hace más fácil planificar las reformas legislativas y hasta la propia configuración de la jurisdicción penal. Desde ese punto de vista, no se pueden tipificar hechos que la sociedad no rechaza, porque encontrarán problemas en la elaboración de la convicción judicial, lo que amenaza con distorsionar todo el modelo. No se podrá caer en el populismo punitivo, porque el supuesto consenso derivado de declaraciones políticas repugnantes no es más que el producto de una manipulación puntual.

Pero podremos decidir, además, qué formación debe tener el juez, a fin de que consiga captar perfectamente esos consensos en cada momento, igual que el legislador, por cierto. Y también se podrá decidir, desde esta perspectiva, si el jurado es un válido representante de la voluntad popular en sociedades numerosas y complejas, o más bien se trata de una reliquia histórica que se convierte en simple farsa representativa en la práctica, víctima además de toda clase de prejuicios.

Por último, cabrá concretar cómo debe ser la respuesta del sistema. Será necesario identificar definitivamente a la pena como una actividad netamente ejecutiva, lo que ayudará a reflexionar, no solamente sobre sus fines, sino sobre sus posibilidades en el sistema de que se trate. Será posible concretar si se sigue tratando de un castigo basado en el Talión, que nuevamente vuelve a estar construido sobre un consenso social viciado, muy inestable y reminiscente de la venganza o autotutela que el Derecho procesal intenta evitar, o más bien cabría decir que hoy en día, cuando probatoriamente podemos conocer el estado mental de un reo a través de diversas pericias, la pena -que quizás debería dejar de llamarse así- debe ser más bien un tratamiento que ayude, no ya a reintegrar al individuo a la sociedad, sino a adecuar su comportamiento futuro a lo dispuesto por el ordenamiento jurídico, entendiendo por qué su conducta es antisocial, existiendo otras vías para conseguir la satisfacción personal, siempre que ello sea científicamente posible, así como procesalmente viable en función de la infraestructura existente en cada territorio.

Restará, finalmente, averiguar qué podemos hacer con los inimputables irrecuperables y con los menores. Más allá del Derecho, debe hablar la psiquiatría ${ }^{76}$ y la neurociencia en estos casos extremos, dictando cuáles son los tratamientos -nuevamente los tratamientosacertados. El sistema integral tendrá que posibilitar la materialización de aquello que diga la ciencia médica.

\section{Conclusiones}

1. Para construir un sistema integral de Derecho penal, es necesario saber en primer lugar qué pretende realmente el Derecho penal con sus normas.

2. El Derecho procesal tiene desde hace tiempo un objetivo completamente unánime en la doctrina: la prevención de la autotutela.

\footnotetext{
${ }^{76}$ Pese a sus imprecisiones, que destaca RAGUÉS i VALLÈS, Ramón, El dolo y su prueba en el proceso penal, Barcelona: Bosch, 1999, p. 230.
} 
NIEVA, Jordi. "Seis conceptos en busca de un objetivo: jurisdicción, acción, proceso, derechos, pena y delito".

3. Más allá de ese fin, el Derecho procesal ha elaborado teorías sobre sus principales conceptos fundamentales que no ayudan realmente a construir ese sistema integral, aunque sí aportan ideas interesantes.

4. En cambio, la teoría de los derechos fundamentales y de los principios sí tienen importancia en ese estudio. Las mismas han servido, sobre todo, para mantener la imparcialidad judicial y la defensa de las partes, que es esencial para objetener un juicio no sesgado psicológicamente.

5. Que el juez no esté sesgado le permite conseguir ser la síntesis del consenso social que siempre se ha perseguido con la emisión del juicio.

6. El Derecho penal intenta establecer un consenso sobre lo más odiado en una sociedad. Siendo ello así, ambos derechos tienen una finalidad coincidente que no posee la mayoría de ramas del ordenamiento jurídico. 
Polít. crim. Vol. 12, № 23 (Julio 2017), Art. 4, pp. 103-123.

[http://www.politicacriminal.cl/Vol_12/n_23/Vol12N23A4.pdf]

\section{BIBLIOGRAFÍA}

ACCURSIUS, Corporis Iustinianaei Digestum Vetus, seu Pandectarum, Vol. 6, Lyon: Sumptibus Horatii Cardon, 1604.

ALBALADEJO, Manuel, Derecho Civil I, Vol. I, Barcelona: Bosch, 1985.

ARTIETA PINEDO, Isabel; GONZÁLEZ LABRA, María José, "La toma de decisiones", en: GONZÁLEZ LABRA, María José, Introducción a la psicología del pensamiento, Madrid: Trotta, 2005.

AZZONE (o AZO o AZÓN), Brocardica (aurea). sive generalia iuris, Basilea: Eusebium Episcopum, 1567.

BULGARUS, "Summa de iudiciis", en: WUNDERLICH, Agathon, Anécdota quae processum civilem spectant, Göttingen: Vandenhoeck et Ruprecht, 1841.

CALAMANDREI, Piero, Instituciones de Derecho Procesal Civil, Vol. I, Trad. SENTÍS MELENDO, Santiago; Buenos Aires: Ediciones Jurídicas Europa-América, 1986.

CARNELUTTI, Francesco, "Ancora sulla lite nel processo penale”, en: EL MISMO, Studi di Diritto Processuale, Padova: CEDAM, 1939.

"Nuove riflessioni sul giudizio giuridico", Rivista di diritto processuale civile, vol. 11, n 1 (1956), pp. 81-106.

CARRERAS LLANSANA, Jorge, "Las fronteras del Juez", en: FENECH, Miguel; CARRERAS, Jorge, Estudios de Derecho Procesal, Barcelona: Bosch, 1962.

DEGENKOLB, Heinrich, Einlassungszwang und Urteilsnorm. Beiträge zur materiellen Theorie der Klagen insbesondere der Anerkennungsklagen, Leipzig: Breitkopf \& Härtel, 1877.

DE GUENYVEAU, Arnault, Du quasi contrat judiciaire, Poitiers: Dupré, 1859.

DE MARINI, Carlo Maria, Il giudizio di equità nel processo civile, Padova: CEDAM, 1959.

DÉMOLOMBE, Jean Charles Florent, Cours de Code Napoléon, Paris: A. Lahure, 1879.

DURANDUS, Speculum iuris, Venecia: Conradi, 1585.

FINUCANE, Melissa; ALHAKAMI, Ali; SLOVIC, Paul; JOHNSON, Stephen M., "The Affect Heuristic in Judgment of Risks and Benefits", Journal of Behavioral Decision Making, vol. 13, $\mathrm{n}^{\circ} 1$ (2000), pp. 1-17.

FOUCAULT, Michel, La verdad y las formas jurídicas, Trad. LYNCH, Barcelona: Gedisa, 1996.

FREUND, Georg, "Sobre la función legitimadora de la idea de fin en el sistema integral de Derecho penal", en: AAVV, El sistema integral del Derecho penal, Madrid: Marcial Pons, 2004.

FURNO, Carlo, "Intervento del prof. Carlo Furno, straord. dell' Università di Perugia", en: AAVV, Atti del Congreso internazionale di diritto processuale civile, Padova: CEDAM, 1953.

GARCÍA DE ENTERRÍA, Eduardo; FERNÁNDEZ, Tomás Ramón, Curso de Derecho Administrativo, I, Madrid: Civitas, 1992.

GIGERENZER, Gerd, Decisiones intuitivas, Barcelona: Ariel, 2008.

GOLDSCHMIDT, James, Zivilprozeßrecht, Berlin: Springer, 1929.

GREEN, Stuart, Mentir, hacer trampas y apropiarse de lo ajeno, Madrid: Marcial Pons, 2013. 
NIEVA, Jordi. "Seis conceptos en busca de un objetivo: jurisdicción, acción, proceso, derechos, pena y delito".

HELLWIG, Konrad, System des deutschen Zivilprozeßrechts, Darmstadt: Scientia Verlag Aalen, 1980.

JAUERNIG, Othmar; HESS, Burkhard, Zivilprozessrecht, München: C.H. Beck, 2011.

KAHNEMAN, Daniel; SLOVIC, Paul; TVERSKY, Amos, Judgment under Uncertainty: Heuristics and Biases, Cambridge: Cambridge University Press, 1982.

KANTOROWICZ, Hermann (Gnaeus Flavius), Der Kampf um die Rechtswissenschaft, Heidelberg: Winter, 1906.

KELSEN, Hans, Reine Rechtslehre, ed. de Viena 1934, Darmstadt: Scientia Verlag Aalen, 1994.

KÜHNE, Hans Heiner, Strafprozessrecht, Heidelberg: C.F. Müller, 2015.

LACRUZ BERDEJO, José Luis, Elementos de Derecho Civil I, Parte General, Vol. I, Madrid: Dykinson, 2002.

LLEWELLYN, Karl N., Jurisprudence. Realism in Theory and Practice, New Brunswick: Transaction Publishers, 2008.

MALINOWSKI, Bronislaw, Crimen y costumbre en la sociedad salvaje, Trad. ALIER, Barcelona: Ariel, 1982.

MIR PUIG, Santiago, Derecho Penal, parte general, Barcelona: Reppertor, 2011.

MYERS, David G., Intuición. El poder y el peligro del sexto sentido, Trad. SOLANA, Guillermo, Barcelona: Paidós, 2003.

NIEVA FENOLL, Jordi, "Imprecisiones privatistas de la ciencia jurisdiccional”, en: EL MISMO, Jurisdicción y proceso, Madrid: Marcial Pons, 2009.

, La duda en el proceso penal, Madrid: Marcial Pons, 2013. , Derecho Procesal I. Introducción, Madrid: Marcial Pons, 2014.

, "La cattiva reputazione del principio inquisitorio", Rivista trimestrale di diritto e procedura civile, vol. 68, $\mathrm{n}^{\circ} 3$ (2014), pp. 943-970.

, "Ideología y justicia legal (con una hipótesis sobre el origen romano del jurado inglés)", Revista Ius et Praxis, n $^{\circ} 1$ (2016), año 22, pp. 59-86.

PATETTA, Federico, Le ordalie, Torino: Fratelli Bocca Editori, 1890.

PEÑA JUMPA, Antonio, "El poder judicial comunal aymara", en: PEÑA JUMPA, Antonio; CABEDO MALLOL, Vicente; LÓPEZ BÁRCENAS, Francisco, Constituciones, Derecho y Justicia en los pueblos indígenas de América, Lima: Fondo Editorial PUCP, 2002.

PLÓSZ, Alexander, Beiträge zur Theorie des Klagerechts, Leipzig: Verlag von Duncker \& Humblot, 1880.

POZUELO PÉREZ, Laura, "Sobre la responsabilidad penal de un cerebro adolescente", InDret, $\mathrm{n}^{\circ} 2$ (2015), pp. 1-26.

RAGUÉS i VALLÈS, Ramón, El dolo y su prueba en el proceso penal, Barcelona: Bosch, 1999.

"La función del proceso en el sistema integral del Derecho penal: una valoración crítica del estado de la cuestión", en: MAQUEDA, María Luisa; MARTÍN, María; VENTURA, Arturo (Coords.), Derecho Penal para un estado social y democrático de derecho: estudios penales en homenaje al profesor Emilio Octavio de Toledo y Ubieto, Madrid: Universidad Complutense de Madrid, Facultad de Derecho, Servicio de Publicaciones, 2016.

ROSENBERG, Leo; SCHWAB, Karl Heinz; GOTTWALD, Peter, Zivilprozeßrecht, München: C.H. Beck, 2010. 
Polít. crim. Vol. 12, № 23 (Julio 2017), Art. 4, pp. 103-123.

[http://www.politicacriminal.cl/Vol_12/n_23/Vol12N23A4.pdf]

SATTA, Salvatore; PUNZI, Carmine, Diritto Processuale Civile, Padova: CEDAM, 1996.

SEN, Amartya, The Idea of Justice, Cambridge: Allen Lane/Penguin Books, 2009.

SERRA DOMÍNGUEZ, "Jurisdicción”, en: EL MISMO, Estudios de Derecho Procesal, Barcelona: Ariel, 1969.

SLOVIC, Paul; FINUCANE, Melissa; PETERS, Ellen; MacGREGOR, Donald, "Risk as Analysis and Risk as Feelings: Some Thoughts about Affect, Reason, Risk, and Rationality", Risk Analysis, vol. 24, n 2 (2004), pp. 311-322.

VON BÜLOW, Oskar, Die Lehre von den Proceßeinreden und die Proceßvoraussetzungen, Gießen: Emil Roth, 1868.

VON SAVIGNY, Friedrich Karl, System des heutigen römischen Rechts, vol. 6, Darmstadt: Scientia Verlag Aalen, 1974.

WACH, Adolf, Handbuch des deutschen Zivilprozeßrecht, Leipzig: Verlag von Duncker \& Humblot, 1885. , Manual de Derecho procesal Civil, Trad. BANZHAF, Buenos Aires: Ediciones Jurídicas Europa-América, 1977.

WESEL, Uwe, Fast alles, was Recht ist, München: C.H. Beck, 2014.

WINDSCHEID, Bernhard; MUTHER, Theodor, Die actio des römischen zivilrechts, Darmstadt: Scientia Verlag Aalen, 2a ed., 1984.

WOLTER, Jürgen, "Estudio sobre la dogmática y la ordenación de las causas materiales de exclusión, del sobreseimiento del proceso, de la renuncia a la pena y de la atenuación de la misma. Estructuras de un sistema integral que abarque el delito, el proceso penal y la determinación de la pena", en: AAVV, El sistema integral del Derecho penal, Madrid: Marcial Pons, 2004. 